\title{
ASPECTOS FORMATIVOS E SOCIO-CONSTITUTIVOS A PARTIR DA TRÍADE "CORAÇÃO, CABEÇA E MÃOS" EM J. H. PESTALOZZI E NO FILME METRÓPOLIS, DE FRITZ LANG
}

\author{
RAFAEL RODRIGO MUELLER ${ }^{1}$ \\ ORCID: https://orcid.org/0000-0001-6637-2948 \\ ANDRÉ CECHINEL ${ }^{2}$ \\ ORCID: https://orcid.org/0000-0002-6620-3447 \\ ISMAEL GONÇALVES ALVES ${ }^{3}$ \\ ORCID: https://orcid.org/0000-0003-3580-9101
}

\begin{abstract}
RESUMO: À luz da nova onda de movimentos nacionalistas que desponta hoje em diversas partes do mundo e também, em particular, no Brasil, este artigo propõe-se a debater comparativamente a dimensão totalizante da célebre tríade formativa do pedagogo alemão Johann Heinrich Pestalozzi, "coração, cabeça e mãos", bem como a sua reapropriação posterior no filme Metrópolis, de Fritz Lang. Para realizar a aproximação entre a proposta de Pestalozzi e o filme de Lang, o presente artigo divide-se em dois momentos fundamentais, voltando-se, primeiramente, para a concepção teórica da tríade "coração, cabeça e mãos", e, a seguir, para a análise de Metrópolis, enfatizando a sua releitura da tríade formativa aqui em pauta. O que se espera mostrar, em linhas gerais, é tanto o uso conservador a que se submete a fórmula de Pestalozzi quanto a possibilidade de sua reapropriação parcial ou integral para naturalizar desigualdades e censurar o desejo de debatê-las, gesto característico de nosso tempo.
\end{abstract}

Palavras-chave: Educação; Nacionalismo; Pestalozzi; Fritz Lang; Metrópolis.

\section{FORMATIVE AND SOCIO-CONSTITUTIVE ASPECTS FROM THE "HEART, HEAD AND HANDS" IN J. H. PESTALOZZI AND THE FRITZ LANG'S METROPOLIS}

\begin{abstract}
In the light of the new wave of nationalist movements that are emerging today in various parts of the world, and also in Brazil, this article intends to discuss the totalizing dimension of the famous formative triad of German pedagogue Johann Heinrich Pestalozzi, "heart, head, and hands," as well as its subsequent appropriation in the film Metropolis, by Fritz Lang. In order to compare Pestalozzi's proposal and Lang's film, the present paper is divided into two fundamental moments: first, it focuses on the theoretical conception of the triad "heart, head, and hands"; after that, the paper analyzes the movie Metropolis, emphasizing its re-reading of the formative triad here in question. In general, the intention is to call attention both to the conservative use of Pestalozzi's formula and the possibility of its
\end{abstract}

\footnotetext{
${ }^{1}$ Universidade do Extremo Sul Catarinense (PPGE-UNESC). Criciúma, SC, Brasil. < rrmueller@unesc.net>

2 Universidade do Extremo Sul Catarinense (PPGE-UNESC). Criciúma, SC, Brasil. < andrecehinel@unesc.net>

${ }^{3}$ Universidade do Extremo Sul Catarinense (PPGDS-UNESC). Criciúma, SC, Brasil. <iga@unesc.net>
} 
partial or integral appropriation in order to naturalize inequalities and censor the desire to debate them, a characteristic gesture of our time.

Keywords: Nationalism; Pestalozzi; Fritz Lang; Metropolis; Education.

\title{
ASPECTOS FORMATIVOS Y SOCIO-CONSTITUTIVOS A PARTIR DE LA TRÍADE "CORAZÓN, CABEZA Y MANOS" EN J. H. PESTALOZZI Y EN LA PELÍCULA METROPOLIS DE FRITZ LANG
}

\begin{abstract}
RESÚMEN: Considerando la nueva ola de movimientos nacionalistas que despunta hoy en diversas partes del mundo y también, en particular, en Brasil, este artículo se propone debatir comparativamente la dimensión totalizante de la célebre tríada formativa del pedagogo alemán Johann Heinrich Pestalozzi, "corazón, cabeza y manos", así como su reapropiación posterior en la película Metrópolis, de Fritz Lang. Para realizar la aproximación entre la propuesta de Pestalozzi y la película de Lang, el presente artículo se divide en dos momentos fundamentales, volviéndose, primero, hacia la concepción teórica de la tríada "corazón, cabeza y manos", y, después de eso, para el análisis de Metrópolis, enfatizando su relectura de la tríada formativa aquí en pauta. Lo que se espera mostrar, en líneas generales, es tanto el uso conservador a que se somete la fórmula de Pestalozzi como la posibilidad de su reapropiación parcial o integral para naturalizar desigualdades y censurar el deseo de debatirlas, gesto característico de nuestro tiempo.
\end{abstract}

Palabras clave: Nacionalismo; Pestalozzi; Fritz Lang; Metrópolis; Educación.

\section{INTRODUÇÃO}

\footnotetext{
"Além das misérias modernas, aflige-nos toda uma série de misérias herdadas [...] com o seu séquito de relações sociais e políticas anacrônicas. Padecemos não apenas por causa dos vivos, mas também por causa dos mortos" (MARX, 2015, p. 79).
}

Assistimos, desde o início do século XXI, a uma crescente onda de movimentos nacionalistas, alicerçados seja por movimentos sociais ou por partidos de extrema direita, em diversas partes do mundo, particularmente nos países ditos 'desenvolvidos'. Tais movimentos se apresentam historicamente em períodos de crise econômica e social, invocando invariavelmente a proteção, em território nacional, das fronteiras e a ideia de 'soberania', expressa pela individualização políticoeconômica, em detrimento da geopolítica atual calcada na economia de mercado globalizada. Essa individualização se expressa tanto por meio da possibilidade de uma 'defesa dos empregos' diante de um contexto econômico desfavorável, quanto pela 'ameaça externa e alheia às questões nacionais', dos movimentos imigratórios e de refugiados. Conforme reportagem de 2011 presente no site da $\mathrm{BBC}^{4}$, a Europa vem sentindo fortemente os efeitos de movimentos nacionalistas na política partidária em diversos países: na França, a Frente Nacional chegou ao segundo turno das eleições presidenciais de 2017 tendo a xenofobia como base de seu discurso, expressa por meio de posições contra a imigração, o islã e a moeda europeia, o euro. Na Itália, a Liga Norte vem desde 2008 ascendendo nas eleições e obtendo uma ampliação de seu projeto por meio de uma coalizão com o até então primeiro ministro italiano, Silvio Berlusconi. Segundo as palavras de seu líder, Matteo Salvini: "Mudar a Europa, salvar empregos e bloquear a invasão, as boas ideias avançam" (G1, 2017) ${ }^{5}$. O Partido para a Liberdade holandês, na figura de seu líder, Geert Wilders, chegou ao segundo turno das eleições presidenciais de 2016 em uma disputa

\footnotetext{
4 Nacionalismo avança e conquista eleitores na Europa. BBC Brasil. 19 abr. 2011. Disponível em: <http://www.bbc.com/portuguese/noticias/2011/04/110418_nacionalismo_europa_mdb.shtml>. Acesso em: 22/03/2017.

${ }^{5}$ Nacionalismo continua de 'vento em popa' na Europa, apesar da derrota na Holanda. G1, 17 mar. 2017. Disponível em: <http://g1.globo.com/mundo/noticia/nacionalismo-continua-de-vento-em-popa-na-europa-apesar-da-derrota-naholanda.ghtml $>$. Acesso em: 03/05/2017.
} 
acirrada. Na Suíça, desde 1999, o Partido do Povo Suíço tem obtido maioria na assembleia federal, tendo como bandeira o discurso anti-imigração e contra a "islamização" no país. Segundo a BBC (2011), o "apoio ao Partido dos Verdadeiros Finlandeses foi de 4\% nas eleições parlamentares de 2007 para 19\% em 2011", tendo seu discurso centrado na anti-Europa, numa política contrária à imigração e num retorno aos valores tradicionais da cultura finlandesa. Em 2015, o futuro primeiro-ministro finlandês, Juha Sipila, decidiu compor a sua base aliada com os Verdadeiros Finlandeses e outro partido conservador. Na Dinamarca, em 2011, o Partido do Povo Dinamarquês já era o terceiro maior no parlamento, tendo como base uma política anti-imigração e anti-islâmica. Já na Suécia, durante as eleições gerais de 2010, os Democratas da Suécia conseguiram pela primeira vez assentos no Parlamento, sendo o partido orientado por política de restrição imigratória.

Em 2006, o Partido Nacional Democrático, de orientação neonazista, obteve um assento na assembleia legislativa da região de Mecklemburgo-Pomerânia Ocidental, Alemanha. Já o partido de extrema direita, Alternativa para a Alemanha, obteve pela primeira, vez nas eleições estaduais de 2016, uma cadeira no parlamento europeu. Além de uma política anti-imigração pautada em uma ortodoxia conservadora, segundo o jornal El Pais (2016), o partido abriga uma "mixórdia de correntes conservadoras que denunciam o que consideram ser imposições da ideologia de gênero e do politicamente correto, pregando, inclusive, uma aproximação com a Rússia de Vladimir Putin". Compondo esse cenário europeu, a aprovação em 2016, via plebiscito, da saída da Inglaterra da Zona do Euro, movimento que ficou conhecido como Brexit, deu-se em torno de uma revisão sobre sua política interna, culminando com a renúncia do então primeiro-ministro, David Cameron. O economista francês Thomas Piketty em entrevista ao jornal El Pais em 2016 afirmou categoricamente: "Nacionalismo e xenofobia são a resposta mais fácil diante das desigualdades" ${ }^{6}$. Por fim, em 2017, o partido político de extrema direita Alternativa para a Alemanha (AfD), com um declarado discurso islamofóbico e antieuropeu, conquistou cerca 12,9\% dos votos, ocupando o terceiro lugar com 90 cadeiras das 631 que compõem o Bundestag, o Parlamento Alemão. Este feito impôs uma interrupção aos 71 nos de afastamento da extrema direita da vida parlamentar alemã, que desde o final de Segunda Grande Guerra, não elegia representantes.

No Brasil, como desdobramentos políticos e sociais dessa onda nacionalista, vemos o crescimento considerável de casos de xenofobia ${ }^{7}$ e o desenvolvimento de discursos nacional-populistas oriundos de movimentos sociais e figuras político-partidárias que até bem pouco tempo, não possuíam apelo popular. Grupos autodenominados "apartidários", como o Movimento Brasil Livre (MBL) e o Vem Pra Rua, os quais tiveram papel proeminente durante o processo de impeachment da presidenta eleita Dilma Roussef em 2016 - aliados a discursos moralizantes que propagam o retorno ao período ditatorial brasileiro enquanto um suposto anseio popular, provindos de políticos de acentuado teor xenofóbico e discriminatório -, expressam em solo brasileiro a mesma onda nacionalista "de primeiro mundo". Tanto na Europa e Estados Unidos como no Brasil, encontramos elementos no discurso nacionalista que remontam invariavelmente a um "retorno ao passado glorioso", no qual o progresso é o destino escrito na história das nações. Nos EUA, o atual presidente eleito, Donald Trump, utilizou, no decorrer de sua campanha presidencial, o slogan "Make America Great Again", numa referência direta à campanha de Ronald Reagan na década de 1980: “Let's Make America Great Again”. Em recente reportagem do jornal The Times, a candidata do partido da extrema direita francesa Frente Nacional, Marine Le Pen, afirmou em um dos debates durante a corrida presidencial de 2017, a seguinte frase: "Only I can make France great again", numa clara alusão ao slogan presidencial de Trump. E no Brasil,

\footnotetext{
${ }^{6}$ YÁRNOZ, Carlos. Thomas Piketty: Nacionalismo e xenofobia são a resposta mais fácil diante das desigualdades. El Pais. 03 jul. 2016. Disponível em: <http://brasil.elpais.com/brasil/2016/07/01/internacional/1467386507_999162.html>. Acesso em: 22/03/2017.

${ }^{7}$ Segundo reportagem de Pedro Diniz do jornal Folha de São Paulo, o Brasil ocupa o primeiro lugar em homicídios de LGBTs nas Américas, sendo que destes, organizações sociais voltadas a esse grupo estimam que "144 desses homicídios sejam de travestis e transexuais" (FOLHA DE SÃO PAULO, 2017). Disponível em: <http://www1.folha.uol.com.br/cotidiano/2017/05/1884666-brasil-patina-no-combate-a-homofobia-e-vira-lider-emassassinatos-de-lgbts.shtml> Acesso em: 21 ago. 2017.

8 BREMNER, Charles. Only I can make France great again, says Le Pen. The Times. 27 fev. 2017. <https://www.thetimes.co.uk/article/only-i-can-make-france-great-again-says-le-pen-0grpnbhh9>.

Educação em Revista|Belo Horizonte|v.36|e214776|2020
} 
o atual presidente Michel Temer utiliza como lema de seu plano de governo, o mote nacionalista "Ordem e Progresso", investindo nos pilares de uma concepção positivista de mundo, do século XIX.

Neste estudo, sustentamos a tese de que o nacionalismo, e suas diversas manifestações, se constitui a partir de uma exacerbação do individual diante do universal, seja por meio de um enaltecimento patriótico diante da geopolítica global, seja por meio de políticas refratárias aos movimentos imigratórios, ao debate de gênero e à diversidade cultural, ou quando determinados grupos políticos se apropriam da estrutura legislativa e econômica nacional em prol da sobreposição de interesses particulares, a partir de uma biopolítica racista e segregadora (FOUCAULT, 2008). A exaltação do particular em face do todo, estabelece 'naturalmente' uma relação social desigual, seja por meio de classes, gênero, etnias, religião etc., assim como 'naturaliza' uma suposta relação de superioridade e domínio de determinados grupos, como por exemplo: uma dita 'supremacia branca', os povos 'do norte' ante os povos 'do sul', a estrutura patriarcal historicamente constituída em nossa sociedade etc. Diante de tal condição, torna-se sempre tarefa de um indivíduo ou grupo, levar a cabo tal projeto de desigualdade naturalizada, legitimada e instituída por vias ideológicas e que desconsidera a diversidade presente na constituição de um país. Nesse sentido, tais figuras tentam instituir, via discurso político-ideológico, um processo inverso ao que os de fato organiza: universalizar o particular, ou seja, tornar o discurso e os interesses de um determinado grupo ou pessoa representativo de todo um país ou nação. A universalização do particular é uma das características de um processo que tem em sua constituição a naturalização da desigualdade como elemento norteador.

Uma das formas de se instituir ideologicamente a desigualdade no âmbito da constituição histórico-social de uma determinada sociedade, é por meio de uma determinada proposta de educação; nesse caso, tal proposta se expressa tanto em nível de formação humana individual quanto em termos de constituição social. Assim, como forma de averiguar o complexo ideológico que institui a universalização do particular, bem como a naturalização da desigualdade, o presente ensaio propõe-se a analisar como a tríade formativa situada no núcleo da proposta educacional do pedagogo alemão Johann Heinrich Pestalozzi (1746-1827), qual seja, "coração, cabeça e mãos", se vincula à frase presente na obra cinematográfica Metrópolis ${ }^{9}$ (1927), de Fritz Lang ${ }^{10}$ (1890-1976), baseada no romance homônimo (1925) de Thea von Harbou" (1888-1954), que, aliás, introduz a passagem em questão: "O mediador entre a cabeça e as mãos deve ser o coração".

A relação entre a tríade formativa de Pestalozzi e a frase presente em Metrópolis seria, em nossa hipótese, a expressão da naturalização da desigualdade tanto em nível formativo quanto sócioconstitutivo. Tais elementos, indicados e constituídos em diferentes épocas na Europa, particularmente na Alemanha, seriam fundamentais para a produção da síntese mais bem acabada da exarcebação do particular frente ao universal e, consequentemente, de naturalização da desigualdade em âmbito societal: o nacionalismo em suas diversas manifestações. Há, entre esses elementos constitutivos do arcabouço político-ideológico do nacionalismo alemão - a concepção educacional de Pestalozzi e o filme Metrópolis -, certas características recorrentes, tais como: o "retorno ao passado", a soberania do individualismo, o sentimentalismo frente à razão pura e elementos conservadores que enaltecem valores tradicionais de uma dada cultura preservada incólume, características que remetem ao Romantismo, período histórico iniciado na Alemanha no século XVIII, ou, mais especificamente, elementos constitutivos de um projeto societal centrado em um modernismo reacionário (HERF, 1993).

A partir de tal relação, não estamos afirmando que a proposta educacional de Pestalozzi ou o filme Metrópolis constituem expressões diretas de um projeto nacionalista, conservador e/ou reacionário, mas sim que suas características podem assumir, dentro de certos contextos, um caráter

\footnotetext{
${ }^{9}$ Filme alemão lançado em 1927 e produzido pelo diretor Friz Lang, é considerado um marco do cinema moderno bem como do expressionismo alemão.

${ }^{10}$ Friedrich Anton Christian Lang, conhecido como Fritz Lang foi um cineasta e produtor que dividiu sua carreira entre a Alemanha e Hollywood. De 1921 a 1934 foi casado com a roteirista Thea Von Harbou, de quem se separou por divergências em relação à adesão ao nazismo, sendo que Thea Von Harbou se vincula ao Partido Nazista e Lang migra inicialmente para França e em seguida para os Estados Unidos.

11 Thea Gabriele von Harbou foi uma atriz, cineasta, roteirista e escritora alemã. Ficou conhecida pela adaptação de sua obra Metropolis (1927) para o cinema. Aderiu ao Partido Nazista a partir de 1933 produzindo e dirigindo dois filmes nessa época. Educação em Revista|Belo Horizonte|v.36|e214776|2020
} 
instrumental-ideológico no que se refere ao nacionalismo em sua naturalização da desigualdade e exacerbação dos interesses individuais frente aos do coletivo.

Como forma de expressar objetivamente nossa discussão, pretendemos estabelecer mediações entre as obras de Pestalozzi e o filme de Fritz Lang, bem como entre estas e a complexa dinâmica histórica, social e cultural de suas épocas a partir da tríade "coração, cabeça e mãos", expressa na estrutura de nosso texto. Desse modo, identificamos possibilidades de compreender como a tríade e sua presença em obras aparentemente desconexas criam condições reais para o desenvolvimento de uma concepção de mundo (Weltanschauung) - e consequentemente de formação humana -, romântica, na qual o melhoramento do tempo presente só é possível via resgate de valores morais e ideias contidas em um passado virtuoso onde o ser humano (singular) não estabelece qualquer relação com a humanidade (universal). Nessa concepção de mundo, o ser humano não toma como elemento necessário e imprescindível para a própria formação, a sua relação com o gênero humano: o "eu" se afirma por ele mesmo sem a necessidade de instituir sua individualidade na relação com o outro, pela expressão de si no outro. Tal visão não é característica unívoca do Romantismo, conforme apresentado por Löwy e Sayre (2015), mas sim uma expressão restrita desse movimento cultural enquanto forma de justificativa e legitimação de uma concepção de mundo marcada por um conservadorismo reacionário naturalizador de desigualdades, característico de nosso tempo.

\title{
A TRÍADE FORMATIVA DE J. H. PESTALOZZI: INDIVIDUALIZANDO PARA INTEGRAR
}

\begin{abstract}
"Os grandes proponentes do nacionalismo de classe média [...] foram as camadas média e inferior das categorias profissionais, administrativas e intelectuais, ou sejam, as classes educadas" (HOBSBAWN, 2016, p. 102)
\end{abstract}

Sob as luzes e sombras que caracterizam o período tido por Hobsbawm (2016) como a "era das revoluções" (1789-1848), tanto a Revolução Francesa quanto a Revolução Industrial marcaram de forma indelével o desenvolvimento da Europa, bem como o da sociedade burguesa que então se constituía. O impacto de tais revoluções na estrutura societal europeia revelou-se por uma constante dualidade: mudança e permanência, novo e velho, tradição e revolução. Ao mesmo tempo que tais revoluções conduziram a mudanças significativas na forma de agir e pensar, também demandaram novas formas de controle e organização social. A burguesia, classe em ascensão em tal período, incorporaria e expressaria tal dualidade tanto por sua participação ativa na Revolução Francesa quanto por sua busca incessante pela organização social que a Revolução Industrial demandava. Nesse caso, o papel central a ser desempenhado era o de criar homogeneidade e integração social frente à heterogeneidade e às individualidades, ou seja, a constituição de um modelo ideal tanto de sociedade quanto de indivíduo. Tal modelo se expressaria no e pelo "espírito burguês" e, para tanto, o meio ideal de disseminação dos valores e ideais burgueses a serem incorporados pelo restante da sociedade (o povo) - e que se constituiria, por tal condição, como de suma importância para a organização e controle social -, seria a educação. Para Arce (2002), o ideal de sujeito burguês residia na bonança material, que dependeria pouco do nascimento e muito do esforço individual e talento no trabalho. No entanto, partindo de um pressuposto de que a organização social por classes seria algo de ordem natural, ou seja, partindo da naturalização daquilo que é social, tal condição só seria possível de duas formas: pela condição financeira ou pela educação. Como para a maioria da população a primeira opção não era a regra, restava à educação ser o campo de possibilidades reais de ascensão social.

Conforme Cambi (1999), a burguesia tem uma compreensão de cunho paternalista acerca da educação, segundo a qual o povo deve ser educado, no intuito de evitar convulsões sociais, por meio da incorporação de valores como o trabalho, a poupança e o sacrifício, ao passo que tais valores, ao serem incorporados, determinariam o sucesso ou o fracasso individual. Caberia então à educação a tarefa não só de adequar os indivíduos à ordem estabelecida, mas também estimular as suas potencialidades (individualidades) para que estas possibilitassem a ascensão financeira, bem como a prosperidade social 
e espiritual. É nesse campo de possibilidades, criadas entre a integração social e o estímulo das individualidades, nas quais a educação tem sua incumbência, que iremos encontrar a figura do pedagogo suíço-alemão Johann Heinrich Pestalozzi (1746-1827) e sua pedagogia romântica simbolizada pela tríade "coração, cabeça e mãos"

Mãe feliz! Te deleitas com os primeiros esforços da criança, que são realmente deliciosos; medita sobre eles; não o esqueças, pois são o gérmen das ações futuras; são muito importantes para ti e para ele, e devem provocar em ti o curso de um pensamento oportuno. Deus concedeu a teu filho todas as faculdades na nossa natureza, porém o ponto essencial permanece indefinido. Para que fins serão utilizados este coração, esta cabeça e estas mãos? A serviço de que irão se dedicar? Esta é uma pergunta cuja resposta envolve um futuro de felicidade ou de infortúnio para a vida que te é tão cara. (PESTALOZZI, 2006, p. 08).

O século XIX inicia com um conjunto de elementos que, ao se inter-relacionarem expressariam uma "revolução cultural", tanto devido a sua origem iluminista, expressa pela filosofia de Kant, pela literatura de Goethe e pelas ciências por Humboldt, quanto pelos ideais de liberdade e igualdade presentes na Revolução Francesa. Tal conjunto de componentes da cultura, identificados particularmente na Alemanha, se interligam a partir de uma concepção de mundo tipicamente romântica, paradoxalmente marcada pelo seu acento ao indivíduo, ao imaginário e fantástico, à tradição, à exaltação dos sentimentos, à ideia de pertencimento e à religião. Tal revolução cultural, que paulatinamente abrangeu grande parte da Europa, compreende uma série de componentes que remetem a temas tipicamente alemães, marcados, segundo Cambi (1999, p. 415), "por uma cultura fortemente espiritualista, tradicionalista e liberal, atenta, ao mesmo tempo, aos temas do conflito, do trágico, do heroico, assim como aos da nação, do povo e da história”.

No seio deste contexto cultural encontra-se a pedagogia romântica alemã, a qual compreendia o saber educativo como um elo entre a filosofia e a ciência, um prenúncio da pedagogia moderna, passando a gozar de grande prestígio na Europa e Estados Unidos. O romantismo pedagógico alemão tem na figura de Pestalozz $1^{13}$ o seu maior expoente, o qual buscava reintegrar aquilo que Rousseau separou: a liberdade da natureza - o desejo natural - e a autoridade do dever - a obrigação. (ABBAGNANO, VISALBERGHI, 1981; SOËTARD, 2010). Seu primeiro experimento educativo se deu na benfeitoria de sua propriedade denominada Neuhof (1767), onde acolhia jovens órfãos a fim de educá-los para a vida produtiva através da execução de diversas atividades laborais, uma protoforma de educação profissional (ABBAGNANO, 1981). De acordo com Hubert (1976, p. 260), essa proposta tinha por princípio "tirar a gente do campo da ignorância e da miséria [...] com uma educação que associe o trabalho manual à aquisição dos conhecimentos elementares". Pestalozzi via na relação entre trabalho e educação um meio de preparar o indivíduo oriundo da população pobre para uma profissão qualificada, o qual, sem essa, estaria condenado ao trabalho estritamente braçal. Mesmo com o fracasso da experiência em Neuhof, evidenciado quando de sua falência, Pestalozzi avança em seus estudos pedagógicos-filosóficos pelo contato com Fichte, pela leitura de Kant e pelo eudemonismo de Rousseau. Continua seus experimentos em Stans (1798), um instituto para órfãos que tinha por proposta a sua organização tal qual a de uma família, propiciando uma educação moral e intelectual aos alunos. Obtendo reconhecimento pelo seu método intuitivo e ensino mútuo ${ }^{14}$, Pestalozzi segue para Burgdorf, onde

12 O lema de Pestalozzi, segundo Barnard (1859, p. 32, tradução nossa), era: "A educação tem de trabalhar a cabeça, a mão e o coração". Do mesmo modo, encontramos em Tröhler (2013, p. 71, tradução nossa) a seguinte referência à tríade pestalozziana: "Contra o pano de fundo de um mundo completamente corrompido, o que há de bem no mundo - a república da virtude - está nas mãos das mães (amorosas): segundo a concepção de Pestalozzi, a educacionalização dos problemas sociais constitui basicamente um assunto maternal. A harmonia resultante dos três poderes e faculdades humanas, os poderes da cabeça, do coração e da mão, que só pode ser conquistada através da preeminência dos poderes do coração, é, para Pestalozzi, o objetivo do 'método' que ele prometeu ao mundo depois de 1800" (grifos nossos).

${ }^{13}$ Não menos importantes representantes da pedagogia alemã, mas que não serão abordados em nosso ensaio, são as figuras de Richter, Fröbel e Herbart.

${ }^{14}$ Conforme o site do HISTEDBR (2018), o método de ensino intuitivo teve sua ampla generalização a partir da segunda metade do século XIX principalmente na Europa. Dentre suas características era a de ser um método de ensino das classes populares, sendo que sua popularização tem relação com o declínio do ensino escolástico e consequente ascensão da pedagogia moderna. 
recebe constantes visitas de estudiosos, e, posteriormente para Yverdon, em 1805, local onde recebe o devido reconhecimento por parte de figuras ilustres da época (Fichte, Fröbel e Madame de Staël, por exemplo) e onde sua experiência pedagógica se torna modelo para toda a Suíça e Alemanha (CAMBI, 1999). Após 20 anos à frente do Instituto de Iverdon, Pestalozzi decide fechá-lo, retornando à Neuhof, propriedade agora gerenciada por seu neto, local onde falece em 1827.

O pensamento pedagógico de Pestalozzi se estrutura a partir de três grandes concepções formativas: (1) a educação deve ser um processo em perfeito acordo com a natureza, pois só assim é possível despertar as capacidades morais e intelectuais dos indivíduos; (2) a formação integral do ser humano como unidade entre o coração, a cabeça e as mãos (ou arte) deve ser desenvolvida por meio da educação moral, intelectual e profissional; e (3) a educação demanda o ensino (instrução) ou propriamente uma pedagogia. A relação entre natureza, sociedade e moralidade é o que integra seu princípio constitutivo-formativo, mais precisamente expressa em suas bases referenciais: o eudemonismo rousseauniano e a ideia de uma natureza humana que deve ser aperfeiçoada pela educação, a tríade formativa que possibilita a vida em harmonia interna (ser) e externa (sociedade), assim como a submissão a um imperativo de ordem moral, nitidamente kantiano, no qual a disciplina e a resignação diante de um dever social são suas expressões na vida cotidiana (HUBERT, 1976; ABBAGNANO, VISALBERGHI, 1981; CAMBI, 1999). Não à toa, Pestalozzi afirma em seu Diário de 1774 que "[...] Breves momentos de esforço que prontamente se condimentam com alegria e com vivacidade não deprimem a alma [mas sim] fazem brotar calma e felicidade da obediência e da ordem, eis a verdadeira educação para a vida social" (apud ABBAGNANO, VISALBERGHI, 1981, p. 561).

Há em Pestalozzi uma convicção, que se expressa em sua proposta pedagógica, de que obediência, esforço individual e resignação são fundamentais para o aperfeiçoamento moral e, consequentemente, para a vida social. Compreender, respeitar e aceitar uma unidade integrada previamente concebida (uma natureza a priori), seja providenciada por meio da religião (ordem moral) e/ou por um processo pedagógico (disciplina social), tornam-se dimensões necessárias e constitutivas da vida individual e coletiva. Nesse sentido, a harmonia social só é passível de ser alcançada por meio de uma educação que garanta tal harmonia no âmbito individual; ou, em outras palavras, como evidencia Soëtard (2010, p. 19), a "ação educativa permite, deste modo, superar o paradoxo de Rousseau que estabelecia a impossibilidade de formar ao mesmo tempo o homem e o cidadão". Para fins de nosso estudo, iremos analisar mais propriamente a tríade formativa "coração, cabeça e mãos", sua relevância para a pedagogia pestalozziana bem como o lugar central que ocupa na constituição da criança e do futuro "cidadão"15.

Diretamente articulada ao seu método pedagógico, a tríade formativa se baseava na integração que havia no ser humano a partir de sua própria natureza e de seu organismo, o qual possuía três dimensões fundamentais: intelectual, físico e moral. Pestalozzi acreditava que cada dimensão é regida por leis imanentes que podem ser localizadas, sendo a tarefa da educação não só identificá-las, mas utilizálas em prol do desenvolvimento da criança. Tal desenvolvimento deve se dar de forma integrada e harmoniosa, porém a primazia será sempre da moral, a qual subordina as outras duas dimensões, pois a "educação ético-religiosa tem, portanto, uma espécie de precedência ideal, e também temporal: é dever dos progenitores cuidar dela desde os primeiríssimos movimentos da criança" (ABBAGNANO, VISALBERGHI, 1981, p. 563).

Sentimento, intelecto e gosto pelo ofício são, para Pestalozzi, as forças essenciais de nosso agir, que devem ser desenvolvidas e estimuladas integralmente com o intuito de incutir valores e responsabilidades diante do outro, seja este a sociedade ou a nação. Soëtard (2010, p. 29) sintetiza da seguinte forma o "princípio pestalozziano" de educação:

[...] o ato educativo somente adquire e conserva seu sentido de ato educativo na medida em que se estabelece uma diferença entre as leis gerais do desenvolvimento da natureza humana em suas três dimensões da cabeça, do coração e da mão, e a maneira em que referidas leis são aplicadas em particular nas situações concretas e nas possibilidades das circunstâncias.

\footnotetext{
15 Pestalozzi é enfático ao afirmar que "nessa circunstância reside o verdadeiro fundamento da educação de um nobre, que é tão importante para os agricultores e para a humanidade; ele deve ser educado, na cabeça e no coração, para o círculo da sua soberania" (apud TRÖHLER, 2013, p. 54).
} 
Se a tríade formativa expressa o desenvolvimento da natureza humana, é certo que ela é válida também para orientar a dinâmica social. Nesse sentido, a pedagogia de Pestalozzi busca a formação do indivíduo para a vida coletiva, em sociedade. Se tal proposta pedagógica visa a providenciar a autonomia tanto em nível individual quanto social, esta só é possível submetendo-se a uma ordem préestabelecida, às leis naturais, cabendo à educação a tarefa de potencializar tal condição por meio da moral religiosa (o coração), do desenvolvimento intelectual (a cabeça) e do trabalho (as mãos). Nesse caso, a autonomia via emancipação só é possível por meio da integração a uma estrutura social pré-estabelecida, em que os valores da burguesia determinavam tais "leis", tomando o sujeito como socializado, integrado, economicamente produtivo e responsável por tal forma social que se constituía industrial e liberal.

Considerando a necessária centralidade instituída à educação no período em questão e identificando Pestalozzi como o melhor representante da pedagogia romântica alemã do século XIX, ao observarmos seus princípios pedagógicos centrados na tríade formativa aqui em pauta, verificamos, então, os elementos ideológicos imputados à educação como sendo inerentes à sua constituição: a pacificação social entre classes e grupos distintos e a homogeneização de determinados valores e comportamentos comuns presentes na cultura burguesa: o trabalho, a poupança, o sacrifício e a colaboração social (CAMBI, 1999). Tais valores representam não somente aqueles de uma classe em particular, mas também expressam por meio da integração formativa e sócio-constitutiva, elementos próprios ao conceito de nação alemã: a integração e homogeneização social, característica particular e exclusiva do povo alemão.

[...] a missão de unificar a humanidade parece a partir de então atribuída, mais do que aos "eruditos", ao "povo alemão" como tal, que tem características por tal forma tão elevadas que é de seu direito e dever tentar levantar até ele também o resto da humanidade [...] Para se preparar para esta missão o povo alemão tem necessidade de uma forma de educação verdadeiramente concreta e alheia ao verbalismo e ao intelectualismo. Fichte aponta Pestalozzi como aquele que realiza uma educação do género. (ABBAGNANO, VISALBERGHI, 1981, p. $545)$

A objetivação de uma pedagogia romântica alemã no século XIX, baseada em uma natureza imanente, como sendo seu destino inefável, identificável e constituinte da ideia de nação, terá implicações políticas, sociais e ideológicas na cultura alemã das primeiras décadas do século $\mathrm{XX}^{16}$, a ponto de se expressar em uma obra como Metrópolis. Dando sequência à nossa análise, pretendemos demonstrar como a tríade formativa pestalozziana embasa um projeto de sociedade futura, a nação alemã mais propriamente, expressa no filme em questão.

\section{METRÓPOLIS E A SOCIEDADE COMO UM ORGANISMO SOCIAL ESTRATIFICADO (“CABEÇA, CORAÇÃO E MÃOS”)}

Fritz Lang ${ }^{1}$, em uma das diversas entrevistas concedidas a respeito de seu filme, relata que, "[...] em Metrópolis" ${ }^{17}$, estava olhando para a Alemanha no futuro" (apud MCGILLIGAN, 2013, p. 104). Tal afirmação é muito significativa para a discussão que aqui estabelecemos, tendo em vista a relação dialética que procuramos perceber entre a pedagogia pestalozziana, a nação alemã e a presente obra. Mesmo que sua frase suscite outras possibilidades de interpretação - como a relação ambígua entre tecnologia e sociedade, por exemplo -, iremos nos deter no aspecto sócio-constitutivo da obra em termos de projeção de uma sociedade paradoxalmente estruturada sobre as bases de um modernismo reacionário no qual o progresso científico-tecnológico convive de maneira integrada com uma concepção de mundo

\footnotetext{
16 Temos ciência de que no período histórico em questão, a denominação correta para a Alemanha seria República de Weimar, porém para fins analíticos decidimos manter a primeira denominação como sendo mais representativa em termos culturais e ideológicos, do momento em que é gestado o projeto nacional-socialista no referido território europeu.

${ }_{17}$ Mesmo que nos remetemos de forma concomitante à obra literária de Thea von Harbou, em nossa análise iremos nos valer da adaptação para o cinema, o filme Metrópolis de 1927, dirigido por Fritz Lang e com roteiro de von Harbou. 
romântica e conservadora. Esse modernismo reacionário, centrado na integração entre technik e kultur, era um elemento central na ideologia do nazismo, conforme expresso por Herf (1993, p. 13):

Antes e depois de os nazistas terem tomado o poder, uma das correntes importantes dentro da ideologia conservadora e subseqüentemente nazista era aquela que buscava conciliar as idéias antimodernistas, românticas e irracionalistas existentes no nacionalismo alemão com a mais óbvia manifestação da racionalidade de meios e fins, isto é, com a tecnologia moderna.

Já em sua abertura, o filme Metrópolis indica sem tardar a metáfora que atravessará os episódios que compõem o seu roteiro: "O mediador entre a cabeça e as mãos deve ser o coração". Os elementos da pedagogia pestalozziana, "cabeça, coração e mãos", recebem em sua versão posterior uma nova interpretação, que tampouco demora para se fazer clara no desenrolar do filme: os trabalhadores (as "mãos") já não suportam mais as precárias condições de trabalho a que se veem submetidos, e estão prestes a se voltar contra as classes dominantes, os "donos" de Metrópolis (a "cabeça", simbolizada no filme por Fredersen, pai de Freder) que organizam a distribuição da cidade nos termos que estão postos. O que impede a revolta popular de simplesmente acontecer é a promessa feita por uma jovem chamada Maria, segundo a qual um "mediador" (o "coração", representado por Freder) estaria para chegar e possibilitar um diálogo apaziguador entre os patrões e as classes trabalhadoras, ou melhor, entre a "cabeça" e as "mãos". Desfeito o laço entre as partes que formam o todo, é a própria cidade que se desfaz, uma vez que, como nos ensina um dos célebres fragmentos de Schlegel (1997, p. 161), cujo impulso totalizante nos explica o que aqui está em jogo, "somente o que está unido com o mundo pode estar unido consigo mesmo". Para existir plenamente, o indivíduo deve se sacrificar em nome de uma totalidade sem a qual ele perde sua identidade.

A estabilidade de Metrópolis depende, portanto, da coexistência relativamente estável e pacífica de um organismo ou corpo social, no entanto, profundamente hierarquizado. Conforme Ludmilla Jordanova (2000, p. 191) comenta, "são várias as alusões no filme a uma harmonia integradora entre as diferentes partes do corpo: 'Entre o cérebro que planeja e as mãos que constroem, deve haver um mediador'; 'É o coração que deve trazer um entendimento entre eles [cérebro e mãos]"'. O que aqui entra em cena, logicamente, é a ideia de uma totalidade - no caso, Metrópolis - que, para funcionar, depende do trabalho que cada um deve desempenhar na maquinaria social, isto é, de uma sintonia global sem a qual a própria organicidade societal é posta em cheque. Em outras palavras, o todo é constituído pela soma de suas partes, e as partes se acomodam em seu devido lugar ao se identificar na arquitetura desse todo. Para o bom equilíbrio entre as partes que desempenham atividades extremamente desiguais e em condições não menos dessemelhantes, o aspecto moral, representado pelo coração, como elemento unificador, tem de estar em pleno funcionamento. O sentimento de pertença se desfaz tão logo o aspecto moral deixe de desempenhar seu papel regulador, que consiste em fazer com que a parte se reconheça num todo que, por vezes, parece distante e indiferente.

Como no caso dos escritos de Pestalozzi, que atribuem à figura materna, como visto, a tarefa de ensinar à criança o equilíbrio entre razão e sentimento, desempenhando, pois, o papel de juiz moral e espiritual ("coração") da formação infantil - "Feliz a mãe que conduz desse modo o seu filho à fé, e da fé ao amor, e do amor à felicidade" (PESTALOZZI, 2006, p. 49). - Maria incorpora, no filme, a dimensão da grande mãe acolhedora, que oferece conforto moral e espiritual aos trabalhadores oprimidos, prometendo a chegada de tempos melhores por meio do mediador que os salvará do abandono. Assim, ouvindo as promessas de tempos melhores, os trabalhadores aflitos se acalmam e voltam a operar pacientemente as máquinas que controlam suas vidas, compreendendo o lugar que ocupam e o papel que devem executar para um funcionamento saudável do todo social e de suas hierarquias. Fica evidente, nesse esquema, que Maria, como o próprio nome indica, é uma personagem "religiosa" que libertará seu povo. As partes do todo só não entram em combustão por conta da promessa de Maria de que as "mãos" e a "cabeça" encontrariam um mediador. Para funcionar, o todo precisa que suas partes estejam bem definidas, articuladas e que desempenhem as suas respectivas tarefas; Maria, em suma, é um dos agentes centrais do equilíbrio social em sua pedagogia da mediação. Tal como nos ensina Schlegel (1997, p. 159) em outro de seus fragmentos, "assim como no homem a nobreza exterior remete ao gênio [à "cabeça”], assim também a beleza das mulheres remete à capacidade do amor, 
ao ânimo". Animar os trabalhadores, mantê-los no âmbito social a eles reservado, eis a tarefa que cabe à beleza de Maria, ordenadora das partes de Metrópolis.

Ora, não por acaso, como se sabe, a metáfora da pátria como mãe que acolhe e nutre os seus filhos foi muito cara à gênese do nacionalismo romântico alemão. Eis o que lemos em Herder, por exemplo, a respeito do poeta e sua relação com a língua materna: "Como, pois, poderia exprimir-me melhor do que em minha língua materna? Como a pátria, ela supera em encanto todas as outras línguas aos olhos daquele que foi o filho de seu coração, o lactante em seu seio, a criança em suas mãos e que agora deverá ser a alegria de seus melhores anos, a esperança e a honra de sua velhice" (HERDER, 2011, p. 33). Escrever em outro idioma significa, em suma, trair os seus, desprezar esta mãe acolhedora e correr o risco de vagar "por regiões desconhecidas, sem pátria e sem deuses familiares" (HERDER, 2011, p. 34). Manter-se no seu devido lugar, por um lado, é respeitar os desejos da grande mãe que acolhe o lactante em seu seio; romper com os desejos dessa mãe implica, por outro lado, ser abandonado, vagar pelo desconhecido sem amparo ou proteção, comprometer a organização da sociedade e desestruturar os laços de irmandade. O que conhecemos por Volkgeist ("espírito do povo"), conceito caro a Herder e ao romantismo alemão, é justamente isso, o sentimento de pertença que unifica e confere identidade aos vários membros de um povo, formando uma totalidade composta de partes mutuamente dependentes, embora por vezes estratificadas de modo estático.

É justamente essa harmonia entre as partes, sustentada por Maria e pela promessa de chegada do mediador, que cai por terra quando do contato da falsa Maria com a classe trabalhadora, agora incitada a destruir as máquinas de que Metrópolis depende para seu devido funcionamento. A rigor, com a chegada da falsa Maria, percebemos quão manipuláveis são os trabalhadores, ou melhor, as "mãos" que compõem o filme: de um corpo angustiado, porém atento à possibilidade de negociação com os patrões por meio do seu futuro mediador, as massas, tão logo a falsa Maria inicia a sua atividade manipuladora, agora se voltam contra as máquinas, destruindo-as com a mesma convicção com que antes as operavam. Nas palavras de R. L. Rutsky (2000, p. 220), "os trabalhadores são apresentados simplesmente como ferramentas 'manipuláveis', como uma tecnologia igualmente suscetível tanto às maquinações emocionais da falsa Maria quanto à mecanização racionalizada de Fredersen". Uma unidade acéfala, emotiva, dependente, influenciável, porém necessária para o funcionamento da cidade - é assim que o filme Metrópolis retrata o mundo do trabalho e dos trabalhadores. Conforme Lotte $\mathrm{H}$. Eisner arremata, as massas nada mais são do que "seres privados de personalidade, com ombros arqueados, acostumados a baixar a cabeça, submissos antes de lutar, escravos vestidos com roupas sem época. Notemos [...] o bloco de operários amontoados nos elevadores, sempre de cabeça baixa, sem existência pessoal" (EISNER, 2002, p. 153). Nesse sentido, quando indica que o "coração" é o mediador entre a "cabeça" e as "mãos", a epígrafe do filme antes anuncia, na verdade, o princípio que impede o descontrole dos trabalhadores, isto é, a moralidade e o sentimentalismo.

Enquanto a verdadeira Maria é a mãe lactante que acolhe e consola seus filhos, uma imagem de pureza, transparência, serenidade, autocontrole e distribuição proporcional ("bela") das partes, a falsa Maria, responsável pela revolução dos operários que destrói a cidade, é apresentada como a Grande Prostituta ou a Prostituta de Babilônia, força destrutiva, desproporcional e profundamente sedutora. A falsa Maria não se ocupa da manutenção da ordem; pelo contrário, ela, como símbolo da sexualidade pulsante e do descontrole, vincula-se aos setes pecados capitais, à destruição das máquinas, ao transbordamento das águas e, assim, à própria morte, uma vez que as águas ameaçam destruir a cidade e suas crianças. Em outras palavras, a falsa Maria, ao estimular que os trabalhadores aniquilem as máquinas e inaugurem um processo de rebelião ou revolta popular, desequilibrando o funcionamento adequado das partes, passa a corresponder a certos emblemas de corrupção e degenerescência, entre os quais o sexo, a dança, a sensualidade e o erotismo. Num corte binário bastante evidente, o filme associa o positivo, de um lado, à Maria, Freder e a um pacifismo obediente que significa a manutenção do sistema reinante; já o negativo, de outro lado, corresponde à insatisfação e à busca por uma sociedade diferente e menos hierarquizada, ou melhor, corresponde à tentativa de perturbar a ordem de produção ali em pauta. Ora, é justamente por isso que transgressão e revolta surgem coladas à falsa Maria, aos sete pecados capitais e à imoralidade. Em suma, a falsa Maria é a personificação imediata da rejeição da tríade pestalloziana tal como reapropriada pelo filme; o que a personagem nega nada mais é do que a máxima 
"O mediador entre a cabeça e as mãos deve ser o coração" como princípio legítimo de organização social e distribuição do mundo sensível:

O seu mediador não veio... Vocês esperaram demais! Chegou a sua vez! Quem é o alimento vivo das máquinas em Metrópolis - !? Quem lubrifica as máquinas com o próprio sangue - !? Quem alimenta as máquinas com a própria carne - !? Que as máquinas passem fome, seus tolos -! Que elas morram - !! Matem-nas - As máquinas - !! (falsa Maria - Metrópolis).

A individualidade apenas se afirma enquanto tal quando reconhece e se vincula à totalidade maior da qual faz parte; essa totalidade, por sua vez, só se sustenta na medida em que é capaz de realizar a soma equilibrada das diferentes partes que integram o todo. Qualquer elemento que represente o risco de desequilibrar ou corromper a simetria conservadora desse esquema surgirá, segundo a tríade "cabeça", "coração" e "mãos", como força disruptiva a ser descartada do sistema. Não devemos estranhar, assim, o desfecho "conciliador" de Metrópolis: a falsa Maria é lançada a uma fogueira e queima em meio a risos descontrolados, ao passo que, logo a seguir, Fredersen, a "cabeça" opressora de Metrópolis, surge em cena cumprimentando o líder dos trabalhadores, num gesto de reconciliação incentivado pela verdadeira Maria e por Freder, que enfim cumpre o aguardado papel de mediador e harmonizador das partes. Por fim, Metrópolis reafirma o seu impulso totalizante inicial, repetindo a célebre frase, "O mediador entre a cabeça e as mãos deve ser o coração!", agora como epílogo do filme.

Ora, o acordo final a que chegam empregador e empregados, em Metrópolis, não significa de modo algum a possibilidade de revisitar aquilo que cabe a cada uma das partes que formam o todo social, ou mesmo de alterar as péssimas condições de trabalho que estão postas aos trabalhadores desde o início do filme. A respeito desse aspecto eminentemente político, o desfecho de Metrópolis não reserva grandes preocupações. A atenção do filme volta-se, isso sim, para um acerto ou ajuste de contas fundamentalmente formal, ou seja, para a reafirmação de um princípio maior capaz de plasmar uma ideia de coletividade ou de articular as partes e acomodá-las numa totalidade supostamente inclusiva e igualitária. O que passa a unir os habitantes de Metrópolis, quando do fim do filme, não são as condições sociais objetivas ou mesmo a possibilidade de deslocar-se na hierarquia até então dominante, mas sim um "novo" imaginário político que se estabiliza como força comunitária de teor romântico-conservador: "O mediador entre a cabeça e as mãos deve ser o coração!". Aos operários, as mãos, aos patrões, o intelecto, tudo isso sob o signo da moralidade, o regime da obediência e em nome de Metrópolis.

\section{CONSIDERAÇÕES FINAIS}

\footnotetext{
"Deve-se fundar o conceito de progresso na idéia da catástrofe. Que tudo "continue assim", isto é a catástrofe. Ela não é o sempre iminente, mas sim o sempre dado. O pensamento de Strindberg: o inferno não é nada a nos acontecer, mas sim esta vida aqui”" (BENJAMIN, 2004, p. 151)
}

Afirmamos, a partir de nosso estudo, que os aspectos formativos e sócio-constitutivos presentes na pedagogia de J. H. Pestalozzi e no filme Metrópolis de Fritz Lang se inter-relacionam de modo a formar um projeto societal no qual as partes e o todo se organizam harmoniosamente, criando a ideia de que este só pode se objetivar a partir de uma prévia ordenação. Nesses termos, a possibilidade de integração só se estabelece quando seus indivíduos atomizados se (con) formam e objetivam se integrar em tal mundo, negando quaisquer possibilidades de ruptura com tal estrutura ao conservá-la e presentificando-a indeterminadamente. Desse modo, tanto as partes (indivíduos) quanto o todo (sociedade) são refratários ao desordenamento, à possibilidade de outra forma social que não seja idêntica àquela até então vivida, importando nada além de um processo incessante de 'formar para integrar', ou seja, de conservar o cotidiano mesmo que, para isso, se retome elementos do passado que se coadunem com o status quo. Ao se naturalizar tal forma social, suas desigualdades são obscurecidas a ponto de se tornarem elementos constituintes dessa e, consequentemente, questioná-las seria questionar a forma em si.

Toda e qualquer forma de crise (contradição) nesse sistema gera um processo de reação em cadeia, de modo a neutralizar seus efeitos e reconstituir seu cotidiano, pois sua desestabilização significa, 
nesses termos, a impossibilidade de seu mantenimento onde tal ordenação, em última instância, se dá por meio da exacerbação do individual frente o universal. Seja por meio da proposta pedagógica inclusiva de Pestalozzi ou pelo modelo societal presente em Metrópolis, ambos afirmam, em certa medida, a preponderância de uma integração social a partir de uma concepção nacionalista: frente às contradições inerentes à forma social e suas consequentes desigualdades, nada seria mais importante, individual e socialmente, do que a instituição e fortalecimento da nação.

Conforme Arce (2002) a crítica de Pestalozzi ao processo revolucionário francês que encerrou o povo helvético na extrema pobreza por meio da desorganização social e violência, não culmina em uma crítica à estrutura de classes desigual da época, mas sim na possibilidade de melhoramento das condições socioeconômicas do povo via caridade da elite: "ele desejava que as classes altas de seu país usassem de seu dinheiro para que o povo pudesse ter casa, escola, igreja, comida e trabalho, os órfãos fossem assistidos" (ARCE, 2002, p. 67). Desse modo, mantém-se a forma social e se constitui uma ideologia que visa reforçar tal forma, nesse caso, o capitalismo e sua expressão fenomênica em tempos de crise: o nacionalismo conservador. Tal ideologia em seu processo totalizante perpassa os diversos sistemas de representação da sociedade, seus valores morais, políticos, artísticos etc., tendo como objetivo-fim

[...] mascarar, sob a aparência de uma igualdade ideal dos indivíduos e de uma unanimidade social mítica, a desigualdade, a injustiça e a opressão que reinam na sociedade e que se traduzem na divisão social do trabalho e na luta de classes. A educação é política, portanto, na medida em que transmite, sob sua forma explícita ou por meio dos modelos de comportamento e dos ideais, ideias políticas, sobretudo aquelas da classe dominante (CHARLOT, 2013, p. 61-62).

Sob o manto da mítica unanimidade social, seja por meio de um projeto de nação vinculado idealmente a um 'clamor popular' ou pela figura de um indivíduo tido como 'o salvador', aquele que irá restituir os 'valores perdidos' (assim como o fez Freder, o mediador, em Metrópolis), vemos projetos nacionalistas e xenófobos se constituírem nos últimos anos em diversos países da Europa, assim como nos EUA, e particularmente no Brasil. Para os idealizadores de tais projetos, a afirmação do eu (nação, grupo ou indivíduo) gera necessariamente a negação do outro (tudo aquilo ou todo aquele que foge, segundo tal pensamento, a uma 'normalidade'). É sobre esse pilar que movimentos sociais no Brasil, como o MBL e o Escola sem Partido, pautam suas reinvindicações: ao invocarem valores morais tidos como organizadores da sociedade e da nação obscurecidos pela máscara da democracia política, tais movimentos instituem o conservadorismo xenofóbico naturalizador de desigualdades e que desconsidera o outro e a diversidade em prol de sua autoafirmação.

Verificamos, a partir do âmbito educacional, expressões da universalização do particular e da naturalização das desigualdades, como por exemplo, na recém-aprovada proposta de reforma do Ensino Médio ${ }^{18}$ nacional, na qual, velhos ideais conservadores e uma concepção de formação humana centrada exclusivamente no indivíduo, são retomadas por amplos setores da sociedade e com apoio dos poderes legislativo e executivo ${ }^{19}$. A tríade formativa subjaz a essa proposta de formação para o indivíduo atomizado, ao apaziguamento de classes expresso pelos itinerários formativos presentes em tal reforma, sendo um destes, a formação técnica e profissional. Ou seja, nesse projeto, a ideia de que alguns, em termos de escolarização, irão acender até o ensino superior e outros se limitarão ao ensino médio profissionalizante está naturalizada, incorporada à própria lógica da formação educacional, além de fragmentar ainda mais uma estrutura educacional já fragilizada historicamente. Tal movimento não é exclusivo do atual período brasileiro, mas característico de momentos considerados de crise, seja essa de ordem política, econômica ou até mesmo moral, na visão dos 'modernistas reacionários' (HERF, 1993). A Alemanha na década de 1920 (aquela de lançamento do filme Metrópolis) passou por um processo de amplas reformas, inclusive educacionais, que historicamente vinham sendo instituídas por vários setores

\footnotetext{
18 Sancionada a partir da Lei n. 13.415 de 16 de fevereiro de 2017.

${ }^{19}$ Conforme reportagem do jornal Folha de São Paulo (2017): Pautas de viés conservador avançam na gestão de Michel Temer. Disponível em: < http://www1.folha.uol.com.br/poder/2017/09/1921276-pautas-de-vies-conservador-avancam-na-gestaode-michel-temer.shtml> Acesso em: 24 set. 2017.
} 
nacionais, particularmente pela elite conservadora, legitimada pela figura dos 'intelectuais mandarins', conforme indica Ringer (2000, p. 60):

Para coroar os planos dos reformadores, o currículo das escolas médias e superiores devia ser ajustado, pelo menos parcialmente, às condições sociais e econômicas modernas. [...] Para isso, não só as escolas vocacionais mas também outros ramos da escola integral deviam fazer experiências com o "ensino profissionalizante" [...]

Tais reformadores estavam convencidos de que a Alemanha, naquele período, passava por uma profunda crise, a qual se expressava por meio da cultura, da educação e de valores morais, tal qual aquela evidenciada pelos trabalhadores de Metrópolis instigados pela figura da falsa Maria, representante de tudo aquilo que iria contra a moral religiosa e a harmonia social. A reforma, assim como o 'mediador' Freder e a 'mãe' Maria, nesse sentido, viria para reestabilizar o ordenamento social e moral colocados em risco pela figura do alter-ego, do outro e de seu reconhecimento.

Nos últimos anos, acompanhamos no Brasil, a instituição de políticas públicas que versam principalmente sobre o reconhecimento de movimentos sociais historicamente menorizados em termos políticos, como aqueles que tratam da diversidade de gênero (feministas e LGBTs), raciais (via política de cotas nas universidades e em concursos públicos), assim como a legitimidade de movimentos sociais como o dos trabalhadores sem terra (MST) e dos sem teto (MTST). Tais políticas afirmativas e o reconhecimento jurídico por parte do Estado desses diversos movimentos e organizações sociais, estão sintetizadas na figura da falsa Maria, o alter-ego da ordem, do progresso e da moral e que a partir da crise de amplo espectro, deflagrada recentemente no Brasil, devem ser destituídas de sua condição política e social pois, segundo os reformadores conservadores, estas seriam inclusive os vetores de tal crise.

O ideal de indivíduo a ser formado nesse contexto deve ser aquele que Bröckling (2016) assume como sendo o "eu empresarial": movido pela lógica da responsabilidade pessoal, pela liberdade de escolha e pela auto-determinação, características que tornam o sujeito (con) formado ao neoliberalismo contemporâneo. Nesse sentido, se relacionam com os anseios políticos, sociais e morais presentes na perspectiva formativa de Pestalozzi em que "cabeça, coração e mãos", cada qual dentro de seus limites pré-definidos, contribuem para o progresso da nação. Em uma concepção formativa centrada na autoafirmação do 'eu', o 'outro' não pode se constituir a não ser de forma subalterna e resignado em sua inferioridade social, tal qual os trabalhadores (as mãos) do submundo de Metrópolis que, pelo aperto de mãos com o gestor Fredersen (a cabeça), aceitaram seu destino (pelo conselho do coração) ao se colocarem novamente sob uma ideologia conservadora expressa por uma 'tradição'. A tradição é a manifestação do passado presentificado ad eternum, no qual o futuro é destituído de sua possibilidade de 'não-lugar' (u-topos): Metrópolis nada mais é do que a visão romântica de um futuro organizado a partir de um projeto social ideal e conservador que permite ao sujeito, e sob esse aspecto, ao outro, adequar-se a uma sociedade naturalmente desigual, centrada em uma ideologia que objetiva, principalmente pelo subterfúgio da crise, universalizar uma concepção de mundo (Weltanschauung) particular.

Toda e qualquer dimensão mobilizadora relacionada ao Romantismo, como bem apontam Löwy e Sayre (2015), em prol de outro mundo possível, pautado por relações sociais não-capitalistas, é convertida em uma concepção de mundo imobilizante que impossibilita qualquer manifestação de um devir orientado por um senso de comunidade e que afirme a relação entre o ser humano (singular) e a humanidade (universal), ou seja, um pensamento romântico que estimule o 'sonho acordado', 'O aindanão ser’ (BLOCH, 2005), para além de uma vida humana reificada, cindida e unilateral, característica de nossa existência na forma social contemporânea.

\section{REFERÊNCIAS}

ABBAgnANO, Nicola; VISAlBerghi, Aldo. História da Pedagogia. Lisboa: Livros Horizonte, 1981.

ARCE, Alessandra. A pedagogia na "era das revoluções": uma análise do pensamento de Pestalozzi e Froebel. Campinas-SP: Autores Associados, 2002. 
BARNARD, Henry. Life, educational principles, and methods of John Henry Pestalozzi. New York: Published by F. C. Brownell, 1859. Disponível em: <http:// www.archive.org/stream/pestalozzipestal00barnrich\#page/n5/mode/2up>. Acesso em: 10 de jan. 2016.

BBC Brasil. Nacionalismo avança e conquista eleitores na Europa; entenda. Disponível em: <https://www.bbc.com/portuguese/noticias/2011/04/110418_nacionalismo_europa_mdb>. Acesso em: 10 de janeiro de 2016.

BENJAMIN, Walter. Obras escolhidas. vol. 3. Charles Baudelaire um lírico no auge do capitalismo. São Paulo:Brasiliense, 2004.

BLOCH, Ernst. O Princípio Esperança. Rio de Janeiro: Contraponto, 2005.

BREMNER, Charles. Only I can make France great again, says Le Pen. The Times. Londres, 27 de fev. de 2017. Disponível em: < https:/ / www.thetimes.co.uk/article/only-i-can-make-france-great-again-saysle-pen-0grpnbhh9>. Acesso em: 05 de junho de 2017.

BRÖCKLING, Ulrich. The entrepreneurial self. Fabricating a new type of subject. London: SAGE Publications, 2016.

CAMBI, Franco. História da pedagogia. São Paulo: EdUNESP, 1999.

CHARLOT, Bernard. A mistificação pedagógica: realidades sociais e processos ideológicos na teoria da educação. São Paulo: Cortez, 2013.

DINIZ, Pedro. Brasil patina no combate à homofobia e vira líder em assassinatos de LGBTs. Folha de São Paulo, 17 mai. 2017.2 Disponível em: <https://www1.folha.uol.com.br/cotidiano/2017/05/1884666-brasil-patina-no-combate-ahomofobia-e-vira-lider-em-assassinatos-de-lgbts.shtml>. Acesso em: 05 de junho de 2017.

DONCEL, Luis. Partido xenófobo obtém resultado histórico e supera sigla de Merkel na Alemanha. E1 Pais. 05 set. 2016. Disponível em:

<http://brasil.elpais.com/brasil/2016/09/04/internacional/1473006281_617652.html>. Acesso em: 22 de março de 2017.

EISNER, Lotte H. A tela demoníaca: as influências de Max Reinhardt e do Expressionismo. 2. ed. São Paulo: Paz e Terra, 2002.

FOLHA DE SÃO PAULO. Pautas de viés conservador avançam na gestão de Michel Temer.

Disponível em: < http://www1.folha.uol.com.br/poder/2017/09/1921276-pautas-de-viesconservador-avancam-na-gestao-de-michel-temer.shtml> Acesso em: 24 de setembro de 2017.

FOUCAULT, Michel. Nascimento da biopolítica: curso dado no College de France (1978-1979). São Paulo: Martins Fontes, 2008.

HERDER, Johann Gottfried. Poesia, língua e terra natal. In: SOUZA, Roberto Acízelo de. (Org.). Uma ideia moderna de literatura. Chapecó: Argos, 2011, p. 32-34.

HERF, Jeffrey. Modernismo reacionário: tecnologia, cultura e política na República de Weimar e no Terceiro Reich. São Paulo/Campinas: Ensaio/Editora da Universidade Estadual de Campinas, 1993. 
HISTEDBR. Glossário. Método intuitivo. Disponível em:

$<$ http://www.histedbr.fe.unicamp.br/navegando/glossario/verb_c_metodo_de_ensino_intuitivo2.htm \#_ftn1>. Acesso em: 18 de junho de 2018.

HOBSBAWN, Eric. A era das revoluções. 1789-1848. 25. ed. São Paulo: Paz e Terra, 2016.

HUBERT, René. História da Pedagogia. 3. ed. São Paulo: Nacional/INC, 1976.

JORDANOVA, Ludmilla. Science, Machines, and Gender. In: MINDEN, Michael; BACHMANN, Holger (Eds.). Fritz Lang's Metropolis: Cinematic Visions of Technology and Fear. New York: Camden House, 2000, 173-195.

LÖWY, Michael; SAYRE, Robert. Revolta e melancolia: o romantismo na contracorrente da modernidade. São Paulo: Boitempo, 2015.

McGILLIGAN, Patrick. Fritz Lang: the nature of the beast. Minneapolis: University of Minnesota Press, 2013.

NACIONALISMO avança e conquista eleitores na Europa; entenda. BBC NEWS BRASIL. Londres, 19 de abr. 2011.2 de Disponível em: <https://www.bbc.com/portuguese/noticias/2011/04/110418_nacionalismo_europa_mdb.shtml>. Acesso em: 22 de mar. De 2017.

NACIONALISMO continua de 'vento em popa' na Europa, apesar da derrota na Holanda. G1. 17 de mar. De 2017. Disponível em: < https://g1.globo.com/mundo/noticia/nacionalismo-continua-devento-em-popa-na-europa-apesar-da-derrota-na-holanda.ghtml>. Acesso em: : 03 de mai. de 2017.

PESTALOZZI, Johann Heinrich. Cartas sobre educación infantil. Estudio preliminar y traducción de José Maria Quintana Cabanas. 3. ed. Madrid: Tecnos, 2006. Disponível em: <https://iessecundaria.files.wordpress.com/2013/02/pestalozzi-johann-cartas-sobre-educacioninfantil1.pdf >. Acesso em: 10 ago. 2017.

RINGER, Fritz. O declínio dos Mandarins Alemães: a comunidade acadêmica alemã, 1890-1933. São Paulo: EdUSP, 2000.

RUTSKY, R. L. The Mediation of Technology and Gender. In: MINDEN, Michael; BACHMANN, Holger (Eds.). Fritz Lang's Metropolis: Cinematic Visions of Technology and Fear. New York: Camden House, 2000, 217-244.

SCHLEGEL, Friedrich. O dialeto dos fragmentos. Tradução, apresentação e notas de Márcio Suzuki. São Paulo: Iluminuras, 1997.

SOËTARD, Michel. Johann Pestalozzi. Recife: Fundação Joaquim Nabuco, Massangana, 2010. (Coleção Educadores).

TRÖHLER, Daniel. Pestalozzi and the Educationalization of the World. New York: Palgrave Macmillan, 2013.

YÁRNOZ, Carlos. Thomas Piketty: Nacionalismo e xenofobia são a resposta mais fácil diante das desigualdades. El Pais. Madri, 03 de jul. de 2016. Disponível em: <http://brasil.elpais.com/brasil/2016/07/01/internacional/1467386507_999162.html>. Acesso em: 22/03/2017. 
Submetido: $30 / 09 / 2018$

Aprovado: 16/04/2019 